\title{
Hydro-electric power development at the Victoria Falls on the Zambesi River
}

\author{
D. D. A. PIESOLD, B. C. WALKeR \& G. B. MURDOCH
}

\section{Mr Piesold}

I would like to draw attention to several important aspects of the project.

95. First, careful examination of the exposed rock faces in the gorges and analysis of joint patterns were found to be of greater value to the engineering of the project than the classical methods of exploration, such as core drilling. Secondly, to reduce the likelihood of rock falls and to control overbreak it was found to be better to excavate in a direction generally at right angles to the river course rather than parallel to it, demonstrating the fact that when cutting its gorges a river follows the lines of greatest weakness.

96. Before commencing work in the basaltic formations at the Victoria Falls a detailed study was undertaken of similar formations in Iceland where underground hydro-electric power stations had been constructed. Despite large differences in the ages of the respective basalts the main problems turned out to be similar. Encapsulated sand pillars or sand filled valleys which 'liquefied' on interconnexion with excavation work caused difficulties and construction delays with serious accidents being narrowly avoided.

97. To reduce roof support in tunnel and power hall excavations it was important to relate profiles to the type of basalt. In the block basalts flat roofs and rectangular tunnel cross-sections avoided rockfalls and reduced overbreak; in the amygdaloidal lavas with no joint form the Gothic arch form was more suitable. These aspects had an important bearing on the speed, quality and cost of construction.

\section{Mr McQueen (for Mr Murdoch)}

The following particulars of two post-commissioning problems may also be of interest.

99. The first concerns the machine cooling water system. The suspended matter in the river water during the flood season was, as expected, considerable. This suspended matter turned out to have a fine sand or silt content, particularly during the construction stage, the particle size ranging from 210 to less than 50 micrometres. Being of an abrasive nature, this sand had a damaging effect on the strainer baskets and on the pressure reducing valves. The solution adopted was to install debris separators utilizing the cyclone principle. The cooling water supply to the turbine shaft gland is drawn from a separate tapping and here again the strainer has been successfully replaced by one operating on the cyclone principle.

100. When these modifications to the machines in the $60 \mathrm{MW}$ station had been completed and had proved to be satisfactory, identical equipment was installed in the $40 \mathrm{MW}$ station.

Paper published Proc. Instn Civ. Engrs, Part 1, 1974, 56, Aug., 275-301. 
101. The second point concerns some localized cavitation damage observed in the cast iron draft tube bend of one of the turbines in the $60 \mathrm{MW}$ station after several years of satisfactory service. This was effectively repaired by welding, using aluminium bronze rods. The setting of the turbines being, if anything, generous by conventional standards, cavitation damage was not expected. It was significant, however, that no cavitation damage occurred on any of the turbine runners in the $60 \mathrm{MW}$ station. A series of experiments involving air admission to these draft tube bends has been initiated and, although not yet complete, it is believed that the results so far are satisfactory.

\section{Mr J. L. M. Bradley, Watermeyer, Legge, Piesold \& Uhlmann}

My involvement with this project started when I was appointed Resident Civil Engineer at the onset of work in 1963. My period on site covered the initial contracts which made up the construction of the $60 \mathrm{MW}$ underground power scheme.

103. There were various problems which arose immediately in carrying out development adjacent to one of the finest natural beauty spots in the world. There was a strong local body of conservationists whose views had to be taken into account. Permission had to be obtained for the felling of each and every tree in the falls area. Close liaison was required with the Railways Administration to ensure that there was no blasting when trains, especially those carrying explosives to the Copperbelt were in the vicinity. A good working relationship had to be maintained between the existing power station staff and the contractors.

104. In order to keep the disruption and damage in the area to a minimum, the contractor's camp and RE's offices at one stage were situated adjacent to the canal intake on the river bank. Although this spot was very attractive, it did have its drawbacks. For instance, when blasting the $60 \mathrm{MW}$ intake, a boulder took off, passed in through one wall of my office and travelled horizontally out through the other end, demolishing the office furniture in the process. Naturally at the time everyone was evacuated for the blast. However, the feeling that I was being ' $g$ ot at' by the contractors was immediately dispelled when it became apparent that the rock had carried on to demolish not only their office but also their store.

105. The river channels leading water to the intakes were carried out by different contractors in the successive contracts and it was interesting to note that the method of undertaking the work was directly related to the firms' main experience and background. The contractor with mining and shaft sinking experience started construction of the rockfill coffer dams in the river with coco pans pushed along light rail track. The second contractor had heavy plant and earth-moving experience and used this approach to advantage: he had, with hindsight, the better approach of the two because of the speed with which it was completed, which minimized problems from impending seasonal floods.

106. I should like to draw attention to the seasonal factor which manifests itself in this part of Africa when carrying out work in or adjacent to major rivers. There are, in fact, only about four months of the year when work is not impeded by natural causes: during the winter period, before the rainy season which starts in OctoberNovember. When the rains tail off, the work becomes affected by the rise in the water level in the river. The flood peak takes place in March/April and the flood recession extends to June. Since the river is a mile wide above the falls, a foot rise there results in a $6-8 \mathrm{ft}$ rise in the gorge.

107. Overtopping of the intake coffer dams by floods and collapse due to downstream erosion of the relatively steep side slopes was experienced. In the latter stages, guide walls were installed in the river using pervious rockfll walls with relatively flat downstream slopes. These have successively been overtopped when the river has been in flood without damage, thus confirming the treatise to that effect.

108. The supply of materials was affected by political events. Initially sand was obtained from a tributary of the Zambesi near Livingstone. When this source was 
depleted other supplies were brought in from further afield. The stone was crushed on site, using fresh basalt spalls from the surface excavations.

109. Cement was originally supplied from a factory near Lusaka. However, when necessity required it, shortfalls were made up from sources outside the country. Reinforcing steel was originally supplied from sources in Rhodesia. After UDI this was not allowed, and all steel had to be purchased through a central State agency in Zambia. These supplies originated from sources in both East and West. Prior to UDI the contractors could obtain materials, tools and spare parts overnight by train from Bulawayo. The political events changed this and items not locally available had to be brought in either from Europe or South Africa.

110. The recruitment of skilled expatriate staff at this time was extremely difficult. The problem was not alleviated by the fact that since the site is of strategic importance the army occupied it for a period, during which they dug in and installed machine gun posts over the site. It is a bit disconcerting when driving in to work in the morning to look at the wrong end of a Bren gun. However, this phase passed and the troops were withdrawn.

111. All this involved the contractors in unforeseen expense, resulting in claims. The contractors had a choice at the time of UDI either to determine the contract or to claim for increased costs in the normal way. They chose the latter approach. Contracts started after these events did not have these particular problems.

112. The time required for mobilization by contractors at the start of work in this part of Africa has not always been fully appreciated. From my experience, it takes months rather than weeks, and any fall-down in logistics can set back a contract, not by the weeks of physical delay involved but by a whole season, as mentioned earlier. The support of the staff of outside agencies such as the railways, road departments and others in these relatively remote regions proved invaluable, and was much appreciated by all on site.

\section{Mr E. M. Gosschalk, Sir William Halcrow \& Partners}

It is clear that the installation of $100 \mathrm{MW}$ in units of $10 \mathrm{MW}$ over a period of some eight years took place in the kind of atmosphere now common, lacking the necessary data which would allow an optimum plan to be programmed and in which data become obsolescent as fast as they can be used. In the circumstances as noted by the Authors, the comparatively low cost achieved of $£ 67 / \mathrm{kW}$ must be regarded as very satisfactory. It is obvious that the adoption of $10 \mathrm{MW}$ units was conditioned by the firm prices obtained for a fraction of the total development. Nevertheless it would be interesting if the Authors could give some indication of the savings which presumably might have been achieved had a smaller number of units-say, five $20 \mathrm{MW}$ units-been adopted. It would seem that this would have been a more convenient and more economical arrangement.

114. It would also be of interest to have some indication of the thinking which led to the superficially rather scrappy provision of three separate power stations of which one only was sited underground. It would seem that at this particular site an important consideration would be the aesthetic appearance. I have never visited the falls but I wonder if everything appropriate was done to achieve an attractive effect and in particular what special provisions were made.

115. The adoption of horizontal generating sets seems somewhat surprising and has not been explained. In general I would have expected that a vertical shaft arrangement would hąve been preferable, for a number of reasons, the most important being the saving in space and hence costs, and also an improvement in efficiency due to the elimination of the additional bend on the discharge side. There is usually the possibility of placing the turbine at a lower level in a vertical arrangement, but it appears that the cavitation troubles experienced have not been attributed to the use of horizontal machines. 
116. In general, the history of the Victoria Falls development is an illustration of the desirability and difficulty of producing and working to a master plan. My firm was engaged in feasibility studies for the Kariba and Kafue projects, and it is very interesting to learn of the proposed development of Katombora rapids, which apparently could lead eventually to an installed capacity of $1250 \mathrm{MW}$ at Victoria Falls. This is over ten times the present installation and it would indeed be interesting to know the lines on which existing stations would be augmented or superseded to achieve such an installation. Surely a major development of this kind would also have immense potential for flood relief and irrigation as well as for hydro-electric power, and some more information on these aspects would also be interesting.

117. It is stated in $\$ 59$ that a grouting programme was implemented throughout the underground works but the grout acceptance was low. In view of this, I wonder if the Authors now consider that grouting was still worthwhile.

118. It is understood from $\S 60$ that no more than $30 \mathrm{ft}$ of roof in the underground station were left unsupported at any time, but it is not clear from Figs 7 and 9 how the concrete roof arch was supported while the side walls were excavated.

119. In $\S 65$ it is stated that the rate of guide vane closure on load rejection was chosen to ensure safe subatmospheric pressure in the tunnels, determined by the limitations of the gunite lining. I would be interested to know what pressures were considered safe and how the figures were deduced.

120. Table 4 shows that the capital cost of the $40 \mathrm{MW}$ scheme was greater than that of the $60 \mathrm{MW}$ scheme. I wonder if the difference was entirely due to inflation or if there were other reasons.

Mr R. J. White, Central Water Planning Unit, formerly Sir Alexander Gibb \& Partners The Authors have devoted part of their Paper to consideration of possible future developments at Victoria Falls and I congratulate them for their perspicacity in so doing. They observe that upstream regulation of the Zambezi will be required if further hydro-electric power is to be generated at Victoria Falls and, based on a 1945 survey, they propose a dam at Katombora rapids to impound some 50 maf and provide almost complete regulation of the Zambezi.

122. It is interesting that just such a dam at Katombora was proposed as long ago as 1925 by Du Toit ${ }^{1}$ but his objective was to divert Zambezi flows for irrigation in the Kalahari region of Bechuanaland, now Botswana. Du Toit's survey included profiles by spirit level of the river banks at Katombora and of the water surfaces of the Zambezi and Chobe as well as tentative contours in the reservoir area. Although this survey is now 50 years old I believe that it is still the best source of information for levels on the Chobe side of the proposed Katombora reservoir. Perhaps the Authors could enlarge on the extent of levelling information in the 1945 survey.

123. Whatever topographic information may one day be revealed by precise levelling of the reservoir area, it is clear that a dam $60-70 \mathrm{ft}$ high at Katombora, as proposed by the Authors, would impound a reservoir with a very large surface area, probably 2000 to 4000 sq. miles. The evaporation losses from the reservoir would be correspondingly large. The Authors have expressed the opinion that with the proposed height of dam at Katombora the additional evaporation losses would be unlikely to exceed 2.5 maf year and this implies that the additional losses attributable to the reservoir would be less than one-third of the net reservoir evaporation. There is considerable uncertainty regarding existing losses from the swamps within the proposed reservoir area but nevertheless I suggest that the additional losses are likely to be a good deal higher than 2.5 maf/year. The large reservoir would cover a substantial area which is not at present subject to flooding. Furthermore, while some $80 \%$ of the Zambezi's flows occur in the six month period from January to June, over $85 \%$ of the net annual evaporation occurs in the remaining six months of the year. Thus net evaporation is highest when the floods have receded. For these and 
other reasons I would expect the additional losses to be approaching the total figures for net reservoir evaporation at Katombora, but detailed hydrological and topographic surveys will be required to take this issue out of the realm of conjecture.

124. The question of evaporation is important because the losses are absolute in terms of downstream flows in the Zambezi. Even the figure of $2.5 \mathrm{maf} /$ year for additional evaporation represents a loss of $8 \%$ of the mean Zambezi flow of 30.6 maf/year quoted by the Authors. The availability of water will be correspondingly reduced at Kariba and Cabora Bassa and also at possible future hydro-electric sites.

125. The Authors have suggested that storage at Katombora would enable the output from the Kariba power station to be materially increased. I submit that the reverse will be true. The large reservoir at Kariba already provides over-year regulation of Zambezi flows and on commissioning of Kariba North the power stations on the north and south banks will pass all Zambezi water through their turbines except at times of exceptionally high flows. Operational studies suggest that the effect on Kariba alone of 2.5 maf/year evaporation losses at Katombora would be an energy generation loss in the order of $700 \mathrm{GWh} / y e a r$ out of $8500 \mathrm{GWh} /$ year total energy generation, the actual figure for the energy loss being dependent on the mode of operation of the schemes. If, as I am suggesting, the evaporation losses are higher than indicated by the Authors, the energy loss at Kariba would be even greater. Such downstream energy losses represent major disbenefits to the development of storage at Katombora and it is important that full account should be taken of these disbenefits.

126. There are also many environmental problems which seem to be somewhat understated by the Authors. Such problems include the visual intrusion of surface works and construction activities, the desirable level of flows at Victoria Falls, the resettlement of small villages in the Katombora reservoir area, the effects of the Chobe game park in Botswana, the limnology of the reservoir, and the hazard of Salvinia auriculata spreading into the Okavango channels.

127. Nevertheless, I agree with the Authors that the greatest difficulty is likely to be that of obtaining international agreement between the four countries affected. If the necessary international agreement can be reached, the natural head at Victoria Falls, in combination with regulation from a reservoir at Katombora, offers an attractive opportunity for the development of cheap hydro-electric power. It is, however, desirable that detailed investigations of this scheme should include evaluation of both alternative scales of development and also the associated disbenefits. Operational studies suggest that such investigations may lead to a lower dam at Katombora and a smaller power installation at Victoria Falls than proposed by the Authors.

\section{Mr B. T. Seddon, Binnie \& Partners}

Mr Gosschalk raised the question of horizontal turbo-alternators. Given the exposed spiral casings and the apparent lack of any sound absorbent finishes in the station I wonder whether the noise level is generally acceptable. Would it be acceptable in a permanently manned underground power station? One important factor in any economic comparison of hydro-electric and thermo-generation is the relative high availability of hydro-electric machines. Could the Authors give a figure on that?

129. The main transformers for the underground power station are apparently located on the surface within the switchyard, and the bus bar mains or the lower voltage cables are about $550 \mathrm{ft}$ long. Generally speaking in large installations it has been suggested that this is about the limiting distance beyond which it is more economical to house transformers in an extension to the turbine cavern. Will the Authors please comment on this point?

130. In $\S 73$ the Authors describe the use of Kastner's method as a guide to the calculation of load distribution between steel tunnel linings, concrete and rock. 
They also refer to the use of steel anchors to resist external pressure. A fairly widely adopted method of calculating the steel thickness to resist internal pressure, where there is adequate rock cover, is to assume that the steel is stressed up to the yield point with no support from concrete or rock. With the thickness adopted by the Authors, and assuming no support, what would be the maximum steel stress as a proportion of the yield?

131. A steel lining of a given thickness embedded in concrete in a rock tunnel may have a collapse pressure under external water loading which is half the internal design pressure. Thus when the groundwater table is high, resistance to external pressure with an empty tunnel often governs design. To provide the necessary additional resistance to external pressure, plate thicknesses can be increased at additional cost to an upper limit of the order of $1 \frac{3}{8}$ in. Above this thickness the site welds will probably require stress relief which is costly and not a practicable proposition in a tunnel. Higher yield strength steels will usually allow a reduction in thickness from internal pressure considerations, but the accepted theories of collapse under external pressure. show that these steels add little to the strength of the lining under external loading.

132. There are three alternatives to thicker linings to resist external pressure:

(a) to limit the external groundwater pressure acting on the lining by aligning the shaft or tunnel as close as practicable to the surface of the rock consistent with the need to ensure adequate cover to resist internal pressure;

(b) to limit the external pressure by drainage galleries or by drainage pipes embedded in the concrete surroundings the steel lining;

(c) to provide, as the Authors have done, external anchorages or stiffeners.

Particularly in the case of multiple steel tunnel linings, $I$ believe that there is a good case for the construction of a minimum diameter drainage tunnel about $100 \mathrm{ft}$ above the centre line of the steel linings. Such a tunnel, with cross adits if necessary, can reduce the external load to not more than the grouting pressure and therefore allow considerable reduction in the weight of steel, leading to significant savings in construction costs.

133. External anchorages to increase the resistance to collapse pressure seem to have been used to a fairly limited extent. This may be partly because they are a nuisance during erection and concreting, but there have also been some doubts regarding the manner in which the anchorages act. Both the Amstutz theory of single lobe buckling failure and the Vaughan theory of symmetrical lobe failure postulate an initial gap between steel and concrete surround which is enlarged due to compression of the steel lining under external pressure prior to failure. To prevent inwards radial movement, therefore, the anchorages acting in tension are required to support the whole of the water load, and if this is accepted, then the anchorages must be at close centres even to support a grout pressure of $50 \mathrm{lb} / \mathrm{sq}$. in.

134. On the other hand, it has been reported that where anchorages spaced about $4 \mathrm{ft}$ apart were used for the Warsak scheme in Pakistan on a $16.5 \mathrm{ft}$ dia. tunnel there was no evidence of anchorage failure under the grout pressure. Because the Amstutz theory postulates that the steel lining slides over the surface of the concrete leading to single lobe buckling, he has proposed shear anchors rather than tension anchors, but these again do not appear to have been used widely. Further information on the anchorages provided by the Authors would be most welcome.

135. In European practice, ultrasonic testing has largely replaced full radiographic examination of welds in steel tunnel linings and pipelines, with radiography confined to weld junctions, to further examination of possible defects and to spot checking. American practice continues to rely largely on radiography.

136. What form of internal protection did the Authors adopt for the steel linings and spiral casings? Coal tar epoxy paint is a common form of protection but it requires thorough surface preparation and careful control during application. 


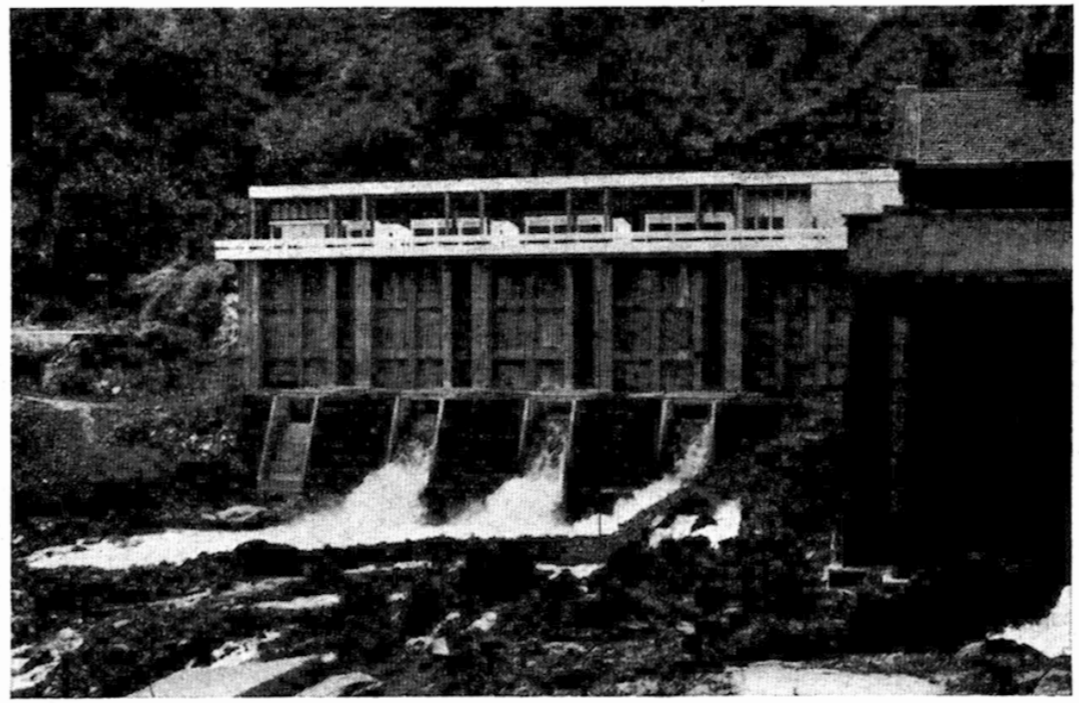

Fig. 15. Power house at base of gorge

\section{Miss Allison Downs, Consulting Architect}

First, I should like to glance back to the end of 1959 when, led by Sir Ove Arup and Mr Edmund Mathews, the problems which arose and the advantages which accrued when engineers and architects collaborated were discussed here at the Institution of Civil Engineers. I am happy to say that those who thought it was an inevitable progression that the professions involved with construction should integrate further were correct, for in my view some 15 years later the barriers have been reduced to the extent that it is now taken for granted that they should work together, and very often under the same roof. As a result, architects have understood more clearly one of their favourite maxims that form follows function, for engineering function, be it in terms of structural stress or form, services or plant, must in every case influence the built form. In some cases engineering function should be the dominant factor from which the whole architectural approach stems, and the power house at the base of the third gorge is a striking example of that type of problem.

138. The outstanding natural beauty of Victoria Falls and the surrounding areas is well known and has already been referred to. It cannot fail to impress deeply all who are fortunate enough to travel there. Although the new surface power house can be seen clearly in elevation from the top of the adjacent cliffs, its position at the base of the gorge gives unusual prominence to the roof which remains fully visible from above. In the first instance, as architects, we were concerned with the visual aspects of the structure below roof level, and then in far greater detail with the roof itself.

139. Figure 15 was taken at the base of the gorge when the river was low. It shows how, with practically no adjustment for aesthetic reasons, the engineering forms give clear expression to the four generating sets and one maintenance bay all below flood level. The gantry supports are related to the main vertical lines of the turbine hall formed by the columns, which also guide the bulkhead gates to the turbine 
DISCUSSION

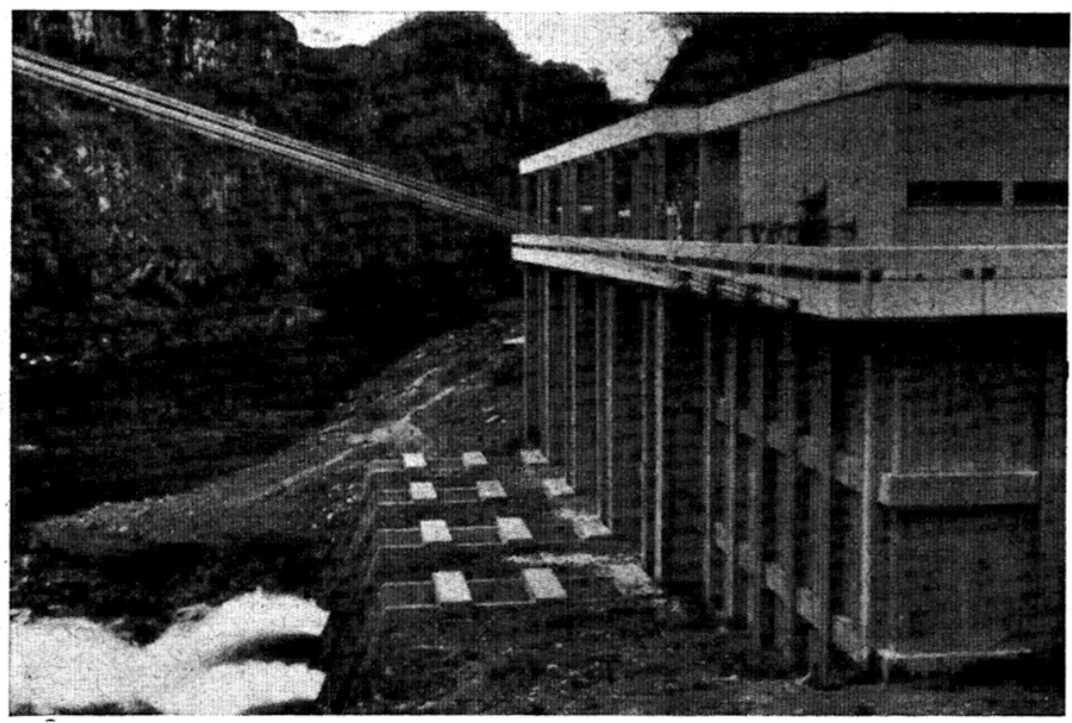

Fig. 16. Detail showing handrailing

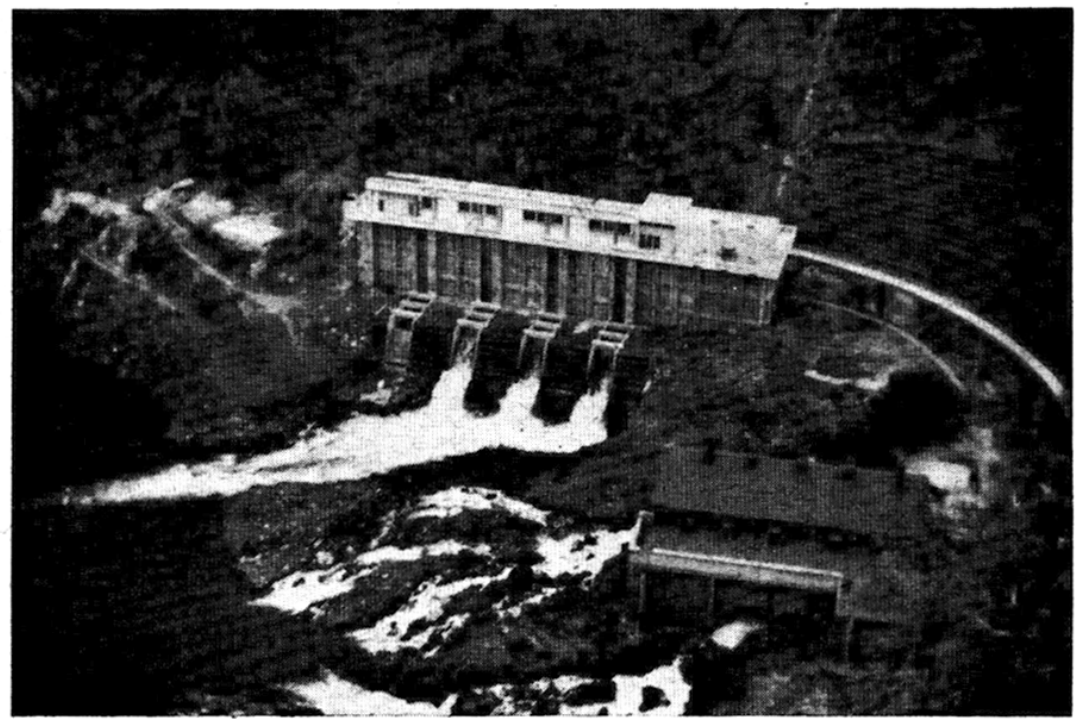

Fig. 17. Power house from cliff top

442

Downloaded by [] on [26/04/23]. Copyright (C) ICE Publishing, all rights reserved. 


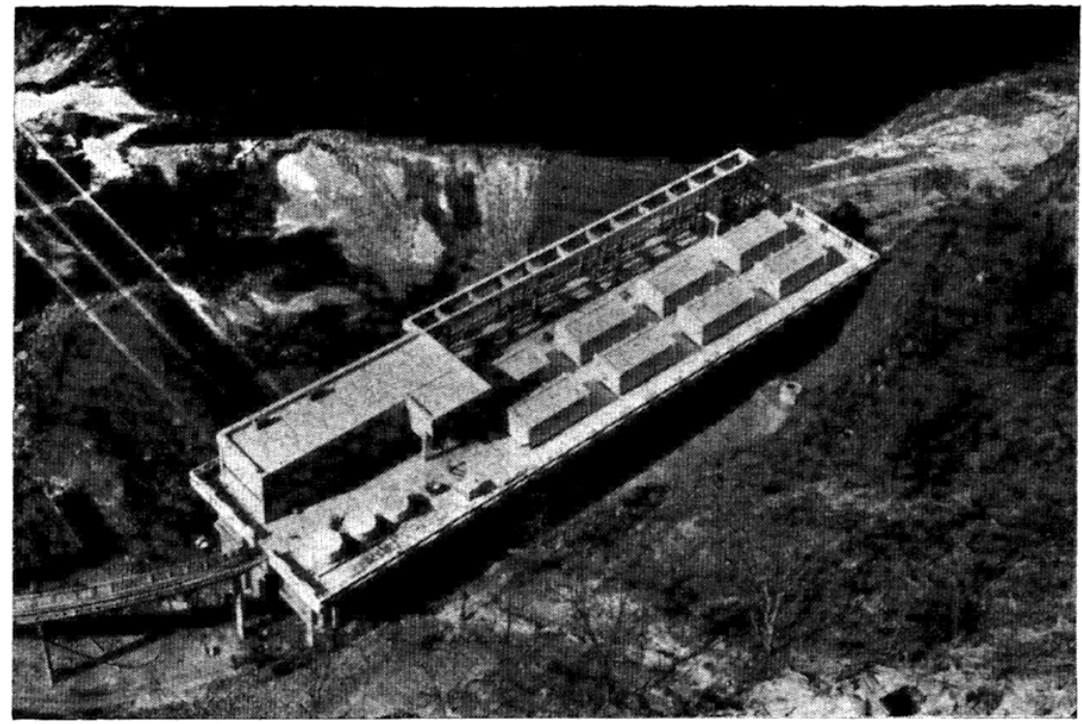

Fig. 18. Power house roof

draft tubes, and the main structure terminates in the firm line formed by the white precast concrete trimming and handrailing to the roof. The latter, which is seen more clearly in Fig. 16, is regarded as an important element of the visual treatment of the power house, and it was sized to eliminate any ambiguity. Above the roof are smaller structures in the form of roof lights orientated towards the south to restrict the penetration of direct sunlight, an office and switchgear room. All these, and the roof itself, are finished with white precast concrete slabs chosen for the maximum reflection of solar gain. The power house as seen from the top of the cliff is illustrated in Fig. 17. This also indicates the access bridge for use when the river is in flood, and which is curved in plan to be in sympathy with the natural formation of the gorge. Finally, in Fig. 18 the power house roof is seen, again from the top of the cliff.

140. As will be appreciated, the site alone gave this project a very special quality. In the architectural sense it fell very naturally into its final and, in my view, logical shape, and when tourists look down on it - as, indeed, they must one day-I hope that it will not detract from their pleasure. It is seldom possible to improve on the natural landscape, and this most certainly was no such occasion: the best to be done is to attempt to be civilized in the approach when the forces of progress make intrusion inevitable.

141. Finally, I should like to thank the engineers here and in Africa who collaborated in a way which will, I am sure, make this project one of my favourite professional experiences.

Mr R. G. T. Lane, Sir Alexander Gibb \& Partners

The developments described in the Paper, the $60 \mathrm{MW}$ underground station and the 40 MW surface station, seem to have been planned before interconnexion with the Central African Power Corporation was considered. Would it not have been possible 
to have improved the output at times of drought by provision of sufficient storage for daily regulation, giving about $15 \%$ greater output at periods of maximum demand?

143. Could this small amount of storage have been further increased and an alteration made to the law governing abstraction from the river to allow for storing water during the night by reduced flow over the falls?

144. As commented by Mr Gosschalk, the size of set seems very small. A single underground station with larger sets would appear more economical.

145. The stations are now interconnected with the CAPCO system, of which the major schemes are Kariba with $100 \mathrm{MW}$ units and Kafue with $150 \mathrm{MW}$ units. The Victoria Falls, Kariba and Kafue schemes have proceeded almost in parallel, and with hindsight it would appear that considerable economies might have been achieved if Victoria Falls had been conceived as part of the overall scheme and to an entirely different scale. The Authors' comments on this would be appreciated.

146. In $\S 31$ it is said: "The reduction of output during moderately severe floods or drought is not a major disadvantage in view of the interconnexion with the CAPCO system, and shortfalls can be made up by generation elsewhere.' It would appear that this is of economic advantage only if the peak demands from the schemes comprising the interconnecting system are out of phase, as wherever the power comes from the plant has to be provided to meet all peaks.

147. Reference is made in $\S 52$ to the presplitting method of excavation for the canals. I visited this site with Mr Walker during the excavation of these canals and I was very impressed with the quality of this work. In $\$ 57$ there is a further reference to overbreak in the power house excavation. There is no doubt about the technical advantages of the various excavation systems known as presplitting, smooth blasting or clean blasting, and it would be very helpful if the Authors could provide figures to indicate the economies of using such techniques. There is still a tendency for contractors under present conditions of contract to prefer the adoption of less controlled and greater blasting charges. I feel that every opportunity should be taken to demonstrate the advantages to both the owner and the contractor of smooth blasting and similar techniques.

\section{The Chairman, Mr R. T. Gerrard}

I notice at the forebay of the $60 \mathrm{MW}$ station that there is a settling basin to extract the coarse elements of sand. This is shown, admittedly on a small scale drawing, as a basin with a flat base. Were any model tests done to optimize the shape to make it most effective in settling particles, and to prove the effectiveness of the means of sluicing out the sediment? How has this basin performed?

149. My second question concerns the surface power station, which is a remarkable structure, subject to 50 or $60 \mathrm{ft}$ fluctuation in tailwater level. Bearing in mind that this had to be designed to allow for thermal expansion, I wonder how it has behaved during high tailwater, whether there have been any seepage problems, and indeed how the main doors to the loading bay have performed. I am not clear what type of doors have been fitted.

\section{Mr A. Hamilton, Watermeyer, Legge, Piesold and Uhlmann, Johannesburg}

I was involved with the Victoria Falls power development from 1969 to 1971 as Resident Engineer for the construction of the $40 \mathrm{MW}$ scheme and my remarks concern the associated construction work.

151. A comparison of daily mid-day temperature and humidity at the site taken during 1970 (which would be representative of most years) shows that the lowest temperature was $67^{\circ} \mathrm{F}$ and the highest temperature $95^{\circ} \mathrm{F}$; the highest and lowest recorded humidities were $87 \%$ and $19 \%$ respectively. The higher daytime temperatures and humidities occurred during the six month rainy season between October and March.

152. The fairly constant tropical heat had its obvious effects on the output of 
site personnel but its effect whilst surveying the principal network of reference beacons is more worthy of comment. The terrain dictated to a large extent the positions of the reference points, some of which were necessarily situated at the foot of the gorge, resulting in longer than desirable distances between points above the cliff and points within the gorges. It was found impossible to obtain accuracy when surveying during the day because of the 'heat-shimmer' and this resulted in all major survey work being carried out between $21.00 \mathrm{~h}$ and $02.00 \mathrm{~h}$ using special illuminated targets.

153. The transportation of materials to the foot of the gorge for the construction of the power station and for the major portion of the tunnel was carried out by two methods. A Blondin aerial cableway linked the power station area with a point just to the north of it and at the top edge of the cliff. All temporary and permanent materials were transported by this means except concrete which was mixed at the top of the cliff and sent down by open chute. The chute was provided, in its $400 \mathrm{ft} d r o p$, with three break-pressure receivers with manually controlled outlets. The position of the chute can be seen in Fig. 5. Continuous monitoring of the concrete crushing strength at the mixer and at the end of the chute never indicated any significant strength change during the remarkable journey of any single batch.

154. One other means of access to the power station was the haulageway constructed under the earlier $8 \mathrm{MW}$ contract. However, the use of this method of transportation was limited to the contractor's plant and to the tunnel lining which because of the heavy loads involved could not be handled by the cableway.

155. Excavation at the site of the power station began in June 1968. An access road was formed from the $8 \mathrm{MW}$ power station along the side of the river and approximately $20 \%$ of the required excavation for the power station was cleared before blasting to the underlying basalt was found necessary. The excavation was completed by October 1968.

156. At the same time as the foundations were being constructed, an earthfill cofferdam was placed round the power station area as protection from the rising river level. By February 1969 the river flow was reaching very high proportions; the eventual overtopping of the cofferdam and the inundation of the works were inevitable. The power station had to be abandoned until mid-May 1969, when the river had dropped sufficiently to permit clearing-up operations.

157. The construction of the power station involved the excavation of 44000 cu. yd of scree and rock and the placing of $10500 \mathrm{cu}$. yd of concrete. An assessment of the contractor's average production figures showed that $960 \mathrm{cu}$. yd of excavation and $148 \mathrm{cu}$. yd of concrete were achieved per week. The surface works between the river and the vertical shaft required the removal of approximately $61500 \mathrm{cu}$. yd of rock and the placing of $9000 \mathrm{cu}$. yd. of concrete.

158. An earth cofferdam, placed under an earlier contract, was built around the site of the $48 \mathrm{MW}$ intake and positioned so as to permit the required flow to enter the adjacent $60 \mathrm{MW}$ intake. Having completed the intake and placed the associated temporary stoplogs the downstream works were then protected against any future rise in river level. It was discovered that the strategic placing of elephant droppings at the upstream face of the stoplogs was a very effective method of sealing the joints against leaks.

159. Attempts were made to remove the cofferdam but the fast flowing river made this operation totally unsuccessful and it had to be abandoned. The adjacent $60 \mathrm{MW}$ needed about 2300 cusecs at the time and the disturbance of the cofferdam scheme below water by the dragline meant that an unacceptable quantity of solid material was entering the waterway and causing damage to the power station's plant. A further attempt to remove the cofferdam was made by closing the upstream end of the river channel referred to in $\S 37$ : this required a complete close-down of the $60 \mathrm{MW}$ scheme. With negligible flow in the channel the new cofferdam was placed, the channel was dewatered and the intake cofferdam was then removed. The complete operation from close-down to start-up took seven weeks. 
160. Blasting in the canal area for construction of the surface works presented a problem due to the close proximity of a newly constructed hotel. A vibrograph was installed in one of the rooms closest to the area of blasting and the subsequent charges were controlled to give acceptable vibration amplitudes.

161. Below-ground works consisted of a small tunnel for the scour syphon, the vertical shaft and headrace tunnel. Normal methods of drilling, charging and blasting were used and the advances for each of these three underground works were $10 \mathrm{ft}$, $5 \mathrm{ft}$ and $7.5 \mathrm{ft}$ per round respectively. The only difficulty experienced in the excavation of the headrace tunnel and the adjacent adit was when the face reached the sandfilled cavities $(\S 83)$. Within the adit strengthening measures were carried out using timber mopani poles for the $41 \mathrm{ft}$ length of the inclusion while in the headrace tunnel permanent steel arch ribs were used across the $20 \mathrm{ft}$ long inclusion.

162. During the duration of the contract the ratio of European personnel to African personnel engaged on construction varied between 1 to 5 and 1 to 9 with an average of approximately 1 to 6 . The maximum number of skilled/unskilled African workers employed by the main civil contractor was 340 .

163. Although on an international basis this scheme would not be considered large or even medium sized, its construction had all the associated problems and difficulties of a much larger scheme. The successful completion of the project says much for all those involved, particularly the contractors and their work force who contributed so much.

\section{Mr A. R. B. Edgecombe, Fellow}

The Paper states that "the ultimate potential of the [Victoria Falls] site could be raised to approximately $750 \mathrm{MW}$ at $100 \%$ load factor. As the present load factor on the CAPCO system is approximately $60 \%$, this would justify the installation of a total of some $1250 \mathrm{MW}$ of generating capacity. This is comparable to the output of either the Kariba or the Kafue hydro-electric schemes'. The 1962-66 Kafue Basin Survey by the Food and Agriculture Organization of the United Nations established that with reservation of $24 \%$ of the regulated surface flow from the component projects for irrigation upstream of Funswe, the ultimate peak power at $75 \%$ load factor would be $825 \mathrm{MW}$, justifying the installation of $963 \mathrm{MW}$ of generating capacity on the Kafue.

165. The great advantage of the Kafue hydro-electric projects over the Victoria Falls is the flow made available for irrigation, which is sufficient to irrigate 1457000 acres of a culturable commanded area of 2380000 acres. A further advantage is that the Kafue River lies entirely in Zambia whereas the Zambesi is international.

\section{Mr G. F. Allison, Central African Power Corporation}

The Central African Power Corporation, through its consulting engineers, has in recent years also investigated the hydro-electric potential of the Victoria Falls including associated storage at Katombora. The investigations were carried out in a wider context, however, and included studies of the hydro-electric potential of the Zambesi river as a whole from above the Victoria Falls to the Mozambique border. Within this section of the river there are at least four sites capable of development on a major scale. The Victoria Falls site presents the only natural high head and the other sites would require development similar to Kariba and Cabora Bassa with high arch or gravity dams. The estimated cost differentials were not found to be very great, however, and with one exception the other sites have the advantage of imposing a lesser influence on the surrounding environment.

167. The estimated annual capacity of $12000 \mathrm{GWh}$ quoted in the Paper for development at the falls is considerably greater than these investigations indicated. This difference appears to derive partly from the concept of upstream storage at Katombora. The Paper suggests a major reservoir of 50 maf with a net evaporation unlikely to exceed $2.5 \mathrm{maf} /$ year. CAPCO's investigations indicated considerably 
greater evapotranspiration loss from the very shallow reservoir which would be created in this area, and suggested an optimum size of more modest proportions which would not require a second embankment to prevent loss of water to the Savuti Channel. Even if the additional loss were no more than 2.5 maf as stated, this could represent a loss in any one year of $750 \mathrm{GWh}$ at Kariba alone, which is almost $9 \%$ of the capacity of the scheme. If the other sites on the Zambesi below Victoria Falls are taken into account the average energy loss would be significant.

168. A further difference in estimating capacity could result from the volume of water assumed for abstraction. In order to ensure no detriment to the natural scenic beauty of the falls our proposals restricted abstraction to that of the Victoria Falls Electricity Board Ordinance of 1954 should the natural flow of the river reduce below 20000 cusec. In addition it would be necessary to develop on both the north and south banks of the river for any such major exploitation and it would be interesting to know what assumptions were made by the Authors regarding these aspects.

169. It has been found in practice that the present run of the river scheme using 4130 cusecs suffers reduction in power output, not only in dry years, but also at normal discharges over the falls. During 1974 output from the three Victoria Falls stations was reduced by as much as $25 \mathrm{MW}$ during October and November despite the fact that normal river flows were being experienced at the time.

170. The Central African Power Corporation system runs at a load factor of approximately $77 \%$, not $60 \%$ as stated in the Paper. As a matter of interest, the Kariba power station has operated at a utilization factor in excess of $95 \%$ of its nominal capacity for the past eight years.

\section{Messrs Piesold, Walker and Murdoch}

We would like to express our appreciation of the interest shown in the Paper, particularly in respect of the future possibilities. Dr D. T. Edmonds, who was at one time responsible to the Federal Power Board for hydrological data on the Zambesi, has been consulted with regard to aspects of the reply.

172. Mr Gosschalk and Mr Lane enquired about the development with smaller units as opposed to one utilizing larger machines in line with those being installed at Kariba and Kafue. The first power station was designed for the small requirements at Livingstone where the load had developed over about 50 years from zero to about $4 \mathrm{MW}$ when the new power plant was projected. There was no thought of interconnexion at that time and the underground station was considered to be sufficient for Livingstone's future demand for a very long time.

173. Mr Gosschalk is correct in suggesting that a smaller number of larger units would have resulted in lower cost; the matter was considered during the project study. As indicated in $\S 35$, the surface station was introduced at a time when the merits of north bank Kariba and Kafue were again under review, and it was found on the load curve that there was a gap before Kafue could be brought into operation. By taking up the earlier options on supply of machines it was apparent that the surface station at Victoria Falls could be implemented more rapidly in order to utilize the capacity of the new $220 \mathrm{kV}$ line and gave roughly one year's 'breather' before the new Kafue station came into being. The variation in cost between the two stations at Victoria Falls was largely due to the increased difficulties in obtaining materials and equipment for the latter.

174. Mr White has correctly stated that further study is required to provide the necessary topographical and hydrological data to prove the benefits of the proposed Chobe reservoir and to take the issue of the evaporation losses out of the realms of conjecture. With regard to our estimate of 2.5 maf for the evaporation losses from the Chobe Swamp, Mr White states that while $80 \%$ of the Zambesi flow occurs in the six months from January to June, over $85 \%$ of the net annual evaporation occurs during the remaining six months. We cannot agree with the latter figure. Some time 
ago experiments were carried out at Kariba to compare the evaporations from a USWB Class A pan and from a disused cooling water tank with a surface area of 2000 sq. $\mathrm{ft}$ and a depth of $4 \mathrm{ft}$. The evaporation from the pan showed marked seasonal variations, with the highest evaporation being recorded in October when losses of over $12 \mathrm{in./month}$ were measured. The tank, in contrast, showed a relatively constant evaporation loss throughout the year. These results appear to indicate that for a very large expanse of water the evaporation would be sensibly constant throughout the year and would be of the order of $65 \mathrm{in}$./year. Thus, if half the rainfall of approximately $25 \mathrm{in}$. is assumed to occur prior to the end of December and the balance thereafter, the net reservoir evaporation in the two periods mentioned would be equal.

175. Further circumstantial evidence of the seasonal uniformity of the evaporation Iosses comes from the water balances carried out during initial filling of the Kariba reservoir. These balances, using the assumed monthly evaporation rates, indicated large apparent losses during the period from late June, through July to early August, in the cool dry season, a time when errors in measuring the inflow are likely to be small. This suggests that the evaporation losses may be underestimated in the cool season and overestimated in late September, October and November owing to the heat storage within a large body of water.

176. So far as we are aware there has been no detailed topographical survey of the Chobe areas since the 1945 survey and our estimates of the surface area and capacity have been based on the rather sketchy data available from that study. The area of the Katombora reservoir at the probable maximum level mentioned in the Paper would be of the order of 3000 sq. miles but the average area during any year is unlikely to be much greater than $2000 \mathrm{sq}$. miles owing to seasonal draw-down. This is comparable to the surface area of Lake Kariba for which the evaporation losses are estimated to be $3.4 \mathrm{maf} /$ year. The area of swamp is approximately $850 \mathrm{sq}$. miles and even if it is assumed that the whole of this area normally dries out in the dry season, then the incremental evaporation losses would be approximately 2.7 maf. However, a large portion of the swamp remains wet throughout the year so that an additional loss of about 2.5 maf seems appropriate.

177. With regard to the losses in electrical output in Kariba and other hydroelectric stations downstream of the proposed Katombora reservoir as mentioned in $\S 167$, these would be partly offset by the ability to operate the stations at a higher head.

178. The total live storage capacity at Kariba is 57 maf between RL 1560 and RL 1605. Of this, 21.5 maf between RL 1590 and RL 1605 is regarded as flood storage. With up to 50 maf of additional storage at Katombora, the long-term average head at Kariba could probably be raised from approximately RL 1580 to RL 1590 , giving a net reduction in output of only $5 \%$, rather than the $9 \%$ quoted by Mr Allison. Furthermore the upstream storage would reduce the spillage loss currently assessed at 3.1 maf, which would still further decrease the overall reduction in output. This loss in electrical energy would be more than offset by the additional energy generated at Katombora.

179. The design of the present run of river hydro-electric installations at Victoria Falls is consistent with the limitations of the earlier Ordinance which rightly restricts the dry season abstraction for power in order to protect the falls: Future development should be accompanied by upstream storage and, for an integrated system, should seek to provide the maximum head with the shortest waterway, irrespective of the geographical boundaries.

180. Consideration has been given to daily storage at Victoria Falls but not in the locality of the present schemes, where the area is flat with little scope for storage of any significance.

181. On the environmental aspects, Miss Downs has replied to the general question: the extent to which construction intrudes should be the minimum possible. The surface power station was chosen for reasons of speed and economy although 
there were difficulties in promoting such a station, particularly with the overhanging rocks. However, timing to make up the one year in the load curve was important, and as we had experienced difficulties in the programme for the underground station, for various reasons we felt we were on stronger ground with a surface station in the circumstances prevailing at the time.

182. Mr Gosschalk raised the question of the choice of horizontal as opposed to vertical machines. It will be appreciated that the deciding factors vary in all hydro stations and it is just a question of evaluating the relative merits at the early design stages. With vertical machines, obviously the foundations have to be lower and the crane rail has to be a little higher, and it was decided that horizontal machines offered the most advantageous compromise for this particular station.

183. Efficiency might have been improved by having vertical machines, but it would not necessarily follow, and if it did the improvement would be marginal. If the efficiency were enhanced due to a change in draft tube design, it would only be a very small fraction of $1 \%$, that being the effect of draft tube efficiency on overall hydraulic efficiency.

184. The cavitation troubles are relatively minor and as explained in the opening remarks are still under investigation. They have not been attributed to the use of horizontal machines and it is expected that additional air admission to the draft tubes will eliminate the problem.

185. Mr Gosschalk also asked about the $8 \mathrm{ft}$ sub-atmospheric pressure for the use of gunite in the draft tube tunnel. This was a calculated figure which it was considered should not be exceeded, and was therefore an influential parameter when consideration was given to machine regulation. Whereas normally the concern is to establish a compromise between pressure rise and speed rise, in this case it was necessary to establish a compromise between speed rise and the negative pressure in the draft tube tunnel. It was calculated that a guide vane closing time of about $12 \mathrm{~s}$ was needed to meet this specific requirement, and this was checked as part of commissioning tests at site. The site test indicated a negative pressure of about $2 \mathrm{~m}$ below the runner. This was safely within the requirements, and so the machines were put into service with a $12 \mathrm{~s}$ guide vane closing time.

186. Mr Seddon also raised the question of horizontal $v s$ vertical machines, asking whether the noise level in the station was acceptable. No complaints have been received, which indicates that the noise level is probably acceptable. When the station was visited some two years ago for a few days one was certainly aware that the machines were running, but the noise level was not troublesome or irritating. The shift operators are in a control room above ground, and very few people are actually in the station for any length of time, except for a few maintenance men. Subject to carrying out a proper investigation with sound level measuring equipment, we would say that the noise level would be acceptable in a permanently manned underground station. This may be due to satisfactory hydraulic and mechanical design, and foundation work.

187. As to machine availability, this is very high and has been utilized to the full in recent years as system demand has grown. A more precise answer to this question could be given only by the Corporation.

188. Mr Seddon correctly says that a distance of $550 \mathrm{ft}$ between main plant and step-up transformers has for some years been regarded as about the limit beyond which it is more economical to locate the transformers underground. Indeed, $500 \mathrm{ft}$ is a published 'break-even' figure based on a study of many underground installations. When the actual distance is close to the 'break-even' figure, a carefully detailed study needs to be undertaken which takes into account many factors: these include the relative costs of high- and low-voltage cables, the transmission and generation voltages, the cost of losses in high- and low-voltage connexions, excavation costs, the cost of removal of additional heat gains in the underground station, the evaluation of 
congestion during construction, etc. In this particular installation, taking all such factors into account, the surface location proved to be more acceptable.

189. Details of the form of internal protection used on the spiral casings was requested by $\mathrm{Mr}$ Seddon who mentioned the thorough surface preparation and careful control required during application. In the case of the Victoria Falls machines the spirals were small enough to be fully fabricated in the works and so the paint treatment was all carried out in the works. No difficulty has been reported.

190. The tunnel linings and penstocks were shot blasted and painted with zinc epoxy paint in the manufacturer's works and subsequently painted with coal tar epoxy paint on completion at site. It is currently normal practice for medium to large spiral casings and penstocks to specify shot blasting followed immediately by twocomponent zinc based epoxy paint. This is usually followed finally by two coats of epoxy based coal tar bitumen paint. It is also becoming common practice to dispense with the zinc based epoxy and apply three coats of bitumen after shot blasting. Opinions vary as to whether the shot blasting and zinc based epoxy application should be carried out in the works or whether the total treatment should be carried out at site. The former can be more economical but, bearing in mind the rough treatment, grout leakages, and other damage which can be done to spiral casings and penstocks during fabrication at site, the latter procedure is more likely to achieve the better results, albeit at some additional cost.

191. On another station, Kariba South, trouble was experienced with the painting of the spiral casings and draft tubes in the early days, but this was due to the impurities in the water caused by rotting vegetation. There was a proportion of $\mathrm{H}_{2} \mathrm{~S}$ in solution which had quite a devastating effect, but the Generation Engineer reports that the problem disappeared after the first year or so of operation and a cheaper and less complex paint specification than the one previously described is giving good results. Much depends, of course, on the chemical make-up of the water and the level from which it is drawn. In Kariba the intakes are well submerged and by the time the water reaches the Kariba Dam, apart from flood times, the abrasive impurities have settled out. As already mentioned there seems to be no problem there now and the relatively cheap paint treatment finally adopted seems quite effective.

192. As the high pressure grout acceptance for the underground works was low (and dependent entirely on the drill-hole striking a fissure in the rock), the extent was subsequently reduced and the pressure was dropped to $50 \mathrm{lb} / \mathrm{sq}$. in. The full extent of the drilling and grouting of the contact between tunnel lining and rock was maintained, however, as this operation was found to be worthwhile, particularly at the top of the arch. Mr Seddon's remarks about the difficulties of anchorage design for the steel tunnel linings are particularly relevant if high grout pressures are specified.

193. The theory used for the external anchors was that developed by Dubas, which assumes evenly distributed anchorages at a spacing similar to the friction anchors discussed by Bachtoldt. The steel lining thickness at Victoria Falls was checked for external pressure and external anchorages were provided where necessary at a spacing somewhat closer than calculated. The anchors were designed to carry a proportion of the load in the arch of the main plate judged necessary to ensure their forming the location of the springing of such an arch; the thickness of the plate allowed for ample reserve on the centres provided. The load distribution factor in the rock-supported zone (between steel, concrete and rock) was checked against the calculated maximum after the initial thickness of steel lining had been determined at near yield stress for the full internal service pressure. The anchors, consisting essentially of long bolts with washer plates, were screwed into nuts previously welded to the outside of the steel linings before casting the concrete encasement. They do not appear to have posed any particular problems. Radiographic examination at site of the welds in the lining by the Site Agent and Resident Engineer was carried out quickly and efficiently and provided no unnecessary cause for delay.

194. In the underground power house, the rock beneath the initial roof arch was 
removed by 'benching' after completion of the arch, except along the sides which were left to support the springing of the roof. The additional sidewall excavation necessary to complete the concrete lining to the level of the operating floor was subsequently completed by 'sliping' blasts in alternate bays of $30 \mathrm{ft}$ so that the arch was always supported. Had the rock been sound the side wall excavation might have been omitted, but the soft scoriaceous basalt was found at lower levels at the southern end of the main hall and the full structural lining was considered necessary.

195. With regard to presplitting or smooth blasting, the form of specification in use for the contracts at Victoria Falls encouraged the contractor to adopt such measures to reduce the thickness of overbreak to the minimum. Where soft material was encountered, however, presplitting was less successful.

196. In answer to Mr Gerrard's questions, the model of the $60 \mathrm{MW}$ settling basin and forebay was concerned with its hydraulic behaviour in regard to vortex formation and surge behaviour and not to particle settlement. The design of the settling basin followed the accepted local practice of monitoring or sluicing the sediment which, on records kept for the original $8 \mathrm{MW}$ station since 1936, is relatively small in quantity, mainly because the river is filtered in the swamps, and natural opportunities for settlement occur. The floor of the pond slopes towards a $36 \mathrm{in}$. dia. outlet pipe and valve in each bay for better physical access during cleaning.

197. Flood protection for the power stations is provided in the form of a heavy door at each entrance, top hung and sliding in the case of the underground access portal and side-hung for the other two. The centre post for the swing doors is normally stored out of the way and is fitted only when the threat of high flood requires the door to be shut and bolted. The later doors have not been tested by the high flood experienced by the original station, but the performance has generally been satisfactory. Seepage through the walls of the surface station at low level during flood stage occurred in the early years, but was subsequently caulked from the outside at low water without difficulty.

\section{Reference}

1. Union of South Africa DePt. Of IrRigation. Report of the Kalahari reconnaissance of 1925. Govt Printing and Statistics Office, Pretona, 1926. 